\title{
Testing the Hypothesis of Contagion Using Multivariate Volatility Models*
}

Emerson Fernandes Marçal**

Pedro L. Valls Pereira**

\begin{abstract}
The aim of this paper is to test whether or not there was evidence of contagion across the various financial crises that assailed some countries in the 1990s. Data on sovereign debt bonds for Brazil, Mexico, Russia and Argentina were used to implement the test. The contagion hypothesis is tested using multivariate volatility models. If there is any evidence of structural break in volatility that can be linked to financial crises, the contagion hypothesis will be confirmed. Results suggest that there is evidence in favor of the contagion hypothesis.
\end{abstract}

Keywords: Contagion, Multivariate Volatility Models.

JEL Codes: G15, C32.

${ }^{*}$ Submitted in July 2006. Revised in August 2008. The authors thank two referees and the Editor of this journal for their comments. Remaining errors are our own. The second author thanks CNPq for partial financial support, process number 480831/2007-6.

${ }^{* *}$ CCSA - Universidade Presbiteriana Mackenzie and EESP-FGV, Rua Itapeva $474,12^{\circ}$ andar, 01332-000 São Paulo, S.P. E-mail: emerson.marcal@fgv.br

${ }^{* * *}$ EESP/FGV. Correspondence to: Pedro L. Valls Pereira, CEQEF and EESP-FGV, Rua Itapeva $474,12^{\circ}$ andar, 01332-000 São Paulo, S.P. Tel: +55 (011) 3281-3726, Fax: +55 (011) 3281-3357. E-mail: pedro.valls@fgv.br

Brazilian Review of Econometrics

v. $28, \mathrm{n}^{\circ} 2$, pp. 191-216 November 2008 


\section{Introduction}

In the 1990s, numerous financial crises assailed several countries, strongly affecting other countries, many of which had few or no commercial or financial relations with the former ones. For instance, different markets suffered the effects of the Mexican crisis in 1995. In this case, closer countries, such as Brazil and Argentina, and faraway countries, such as the Asian ones, without large commercial or financial relationships with Mexico, were affected.

As a result, an attempt was made to measure and test the existence of a contagion effect. The mandatory initial step was to define what contagion precisely meant. Naturally, the assets of countries that were more commercially and economically related tend to have joint movements. A crisis in a given country will spread more easily to another country whose economic ties with this specific country are stronger than to another country whose economic ties are weaker. This fact is related to 'interdependence' rather than to 'contagion'. An extensive financial crisis may go beyond the usual transmission mechanisms and rapidly hit countries which, in another context, would be spared of such events. The idea of financial crisis per se assumes the existence of some kind of 'rupture' with a previous pattern, increasing the probability that a wide range of assets of different countries will be affected by a crisis in a given country. ${ }^{1}$

This paper aims to test the contagion hypothesis using multivariate volatility models. This hypothesis will be tested to check for the evidence of structural breaks in volatility. The paper is organized as follows: Section 2 presents the definitions of contagion and interdependence. Section 3 introduces the multivariate models that will be estimated. Section 4 describes the database used. Section 5 shows the results for the estimated models. Section 6 provides the results for the tests on the break in the variance structure. Section 7 compares the results with the available literature, and Section 8 concludes.

\section{Interdependence versus Contagion: A Brief Literature Review}

There is a vast literature on the alternative definitions of contagion. Some examples include Masson (1998, 1999), Masson and Mussa (1995), Calvo and Reinhart (1996), Forbes and Rigobon (2002), Pesaran and Pick (2003), Dornbush et al. (2000), Pritsker (2001) and Pericoli and Sbracia (2001).

Corsetti et al. (2003) assert that several studies associate an increase in correlation or high volatility with the presence of contagion. Such an assumption can be misleading under certain circumstances. The existence of interdependence is also consistent with correlation or high volatility. Therefore, the authors propose that contagion be associated with an increase in correlation beyond that which is

\footnotetext{
${ }^{1} \mathrm{~A}$ result obtained by Bazdresch and Werner (2000) shows a transmission mechanism of a crisis in which such crisis does not have an equal impact on different markets within the same country.
} 
expected by some interdependence pattern, i.e., contagion would be linked to 'an excessive increase' in correlations between the country that is causing the crisis and all other countries. Suppose that the following linear relationship between the asset returns of two countries in 'calm periods' holds:

$$
r_{i}=\beta_{1} r_{j}+\varepsilon_{i}
$$

where $r_{i}\left(r_{j}\right)$ represents the return of country $i(j)$ and $\varepsilon_{i}$ is a random term. The level of correlation between the returns of country $i$ and $j$ is given by:

$$
\operatorname{corr}\left(r_{i}, r_{j}\right)=\left(1+\frac{\operatorname{var}\left(\varepsilon_{i}\right)}{\beta_{1}^{2} \operatorname{var}\left(r_{j}\right)}\right)
$$

The level of correlation of the returns of assets $i$ and $j$ are positively related to the variance of asset $j$. Note that such result was obtained by postulating a fixed structure for the transmission of volatility. Thus, the increase in correlation in crisis periods may be associated only with some conventional transmission mechanism rather than with contagion.

Dungey et al. (2004) use the following model for the hypothesis of no-contagion for the asset returns under analysis:

$$
\begin{aligned}
& r_{1 t}=\lambda_{1} w_{t}+\delta_{1} u_{1 t} \\
& r_{2 t}=\lambda_{2} w_{t}+\delta_{2} u_{2 t}
\end{aligned}
$$

where $w_{t}$ represents a common term between the two assets; $u_{i t}$ are idiosyncratic shocks. Terms $w_{t}$ and $u_{i t}$ are independent as well as $u_{i t}$ and $u_{j t}$ for any $i \neq j$.

It is possible to demonstrate that:

$$
\begin{aligned}
E\left(r_{1 t} r_{2 t}\right) & =\lambda_{1} \lambda_{2} \sigma_{w t}^{2} \\
E\left(r_{i t}^{2}\right) & =\lambda_{i}^{2} \sigma_{w t}^{2}+\delta_{i}^{2} \sigma_{i t}^{2}
\end{aligned}
$$

Given that country 1 is in crisis and that contagion exists, this turns equation (3) into:

$$
\begin{aligned}
& r_{1 t}=\lambda_{1} w_{t}+\delta_{1} u_{1 t} \\
& r_{2 t}=\lambda_{2} w_{t}+\delta_{2} u_{2 t}+\gamma u_{1 t}
\end{aligned}
$$

It is possible to demonstrate that:

$$
\begin{aligned}
E\left(r_{1 t} r_{2 t}\right) & =\lambda_{1} \lambda_{2} \sigma_{w t}^{2}+\delta_{1} \gamma \sigma_{1 t}^{2} \\
E\left(r_{1 t}^{2}\right) & =\lambda_{1}^{2} \sigma_{w t}^{2}+\delta_{1}^{2} \sigma_{1 t}^{2}
\end{aligned}
$$




$$
E\left(r_{2 t}^{2}\right)=\lambda_{2}^{2} \sigma_{w t}^{2}+\delta_{2}^{2} \sigma_{2 t}^{2}+\gamma^{2} \sigma_{1 t}^{2}
$$

Therefore, if an analyst has such information before the crises, it is possible to test the contagion hypothesis by comparing the structure of correlations between periods. "In particular, contagion has the effect of causing a structural shift during the crisis period in the conditional covariance $\delta_{1} \gamma \sigma_{1 t}^{2}$ and in the conditional variance $\gamma^{2} \sigma_{1 t}^{2} "$ (Dungey et al., 2004).

\section{Econometric Method: Testing the Contagion Hypothesis Using Multivariate Volatility Models}

A vast literature on the modeling of conditional volatility was developed after the original work by Engle (1982) and Bollerslev (1986). The original models were quickly generalized to multivariate versions.

Under the null hypothesis of no contagion, a multivariate GARCH model can be seen as an approximation to the data-generating process, as shown in equation (3). In the presence of contagion, a GARCH model would not be able, at least in principle, to deal with a process such as the one formulated above. There should be evidence of a structural shift, especially in periods of crisis. So, the estimated GARCH model should have some specific signs of misspecification. The existence of contagion implies that (conditional or unconditional) volatility was 'exported' from the country of origin to the country that suffered the contagion and also to the (conditional or unconditional) correlations when a large negative shock was in place. $^{2}$

There exists a literature on specification tests that allows assessing and testing possible sources of misspecification such as residual heteroskedasticity, asymmetric effects on variance, instability of conditional and unconditional structures, among others. These tests can be adapted to investigate whether the sources of misspecification are those suggested in the case of contagion. The major tests used in the literature are those of Wooldridge $(1990,1991)$ and those applied by Engle and Sheppard (2001).

\subsection{Multivariate volatility models available in the literature}

The works developed by Engle (1982), Bollerslev (1986) and Harvey et al. (1994), among others, represent a step forward in the modeling of financial series ${ }^{3}$ through univariate ARCH and GARCH models and stochastic volatility models as well. These models were generalized to multivariate models.

According to the literature, the major problem with multivariate GARCH models lies in the number of parameters to be estimated. Very simple models in terms

\footnotetext{
${ }^{2}$ The investigation could also focus on positive shocks. In this case, it would focus on 'positive' contagion, but this is not within the scope of this paper.

${ }^{3}$ Bollerslev (2001) analyzes the new literature studies on finance in the recent past and points out which areas, in his point of view, are more thriving in a near future.
} 
of generality can quickly become intractable when some assets are added or when a slightly more sophisticated time structure is proposed.

The specification of the multivariate GARCH model is given by: ${ }^{4}$

$$
y_{t}=u_{t}=\varepsilon_{t} H_{t}^{1 / 2}
$$

where $\varepsilon_{t}$ represents a process of dimension $k$ with zero mean and variance/covariance matrix given by an identity matrix of order $k$. By construction, we then have that the distribution of $y_{t}$, given past information, denoted by $I_{t-1}$, satisfies the following properties: $E\left[y_{t} \mid I_{t-1}\right]=0$ and $E\left[y_{t} y_{t}^{\prime} \mid I_{t-1}\right]=H_{t}$. Just as in univariate GARCH models, $H_{t}$ should have some sort of dependence upon the lagged values of $H_{t}$ and of $u_{t}$.

The biggest challenge of this literature was (and still is) to develop models that include both generality and simplicity in their estimation. In the literature, a wide variety of models has been proposed, and the major ones are listed in what follows:

a) VEC (Bollerslev et al., 1988) and BEKK (Engle and Kroner, 1995);

b) Factor models (Lin, 1992), Orthogonal;

c) Constant conditional correlation model (Bollerslev, 1990);

d) Dynamic conditional correlation models (Tse (2000), Tse and Tsui (2002), Engle (2002) and Engle and Sheppard (2001)) and

e) General dynamic covariance model (Bauwens et al., 2003).

\subsection{Specification tests}

With regard to econometric methods, there are two possible approaches to the estimation of a given model. The first approach uses a general model with a set of testable restrictions and simplifications based on the standard Wald or F statistics to obtain a simpler model that describes the data in a virtually equivalent manner.

Another possible approach uses a simple but more specific model and verifies how appropriate the specification is by running a specification test. If the specific model does not provide a good description of the data, the assumption that the simple model is appropriate will be rejected. If that is the case, a more general model is proposed. This type of approach has two major criticisms. Unlike the first approach, the rejection of a model does not necessarily indicate the path to be followed. The second criticism is stronger, though. If the restricted model does not provide a good description of the data, then the estimated parameters are quite likely to be inconsistent and therefore the test results would be compromised.

${ }^{4}$ See, for instance, Franses and van Dijk (2000). 
In the case of multivariate GARCH models, there is not much room for choice as the number of parameters increases dramatically and as they are quite high for models with a relatively simple autoregressive structure. Moreover, the likelihood function is usually nonlinear in its parameters and computationally heavy. The combination of these factors shows that the estimation of these models is cumbersome. $^{5}$

In two papers, Wooldridge $(1990,1991)$ develops robust procedures that can be used to detect a series of possible sources of misspecification based on procedures that involve auxiliary regressions. The great advantage of this approach is that it requires only the estimation of the model under the null hypothesis, since the procedure belongs to the family of Lagrange multipliers. Such procedure has been more widely used in the literature on multivariate models. Engle and Sheppard (2001) and Tse and Tsui (2002) are two examples of this.

The procedure consists in testing to what extent a given variable is useful in predicting the estimated residuals of a model. The test can be implemented as follows. Defining the generalized residuals by $\phi_{t}=\frac{u_{t}^{2}}{h_{t}}-1$ and; $\lambda_{g, t}$, the indicator variables, as the variables or functions of variables that can have predictive power over the residuals; $\nabla_{\theta} \tilde{\nu}_{t} \equiv \frac{\nabla_{\theta} h_{t}}{h_{t}}$, as the gradient value of the estimated variances and $\theta$ an estimate of the model's parameters with convergence rate equal to $T^{0,5}$ and $\tilde{\lambda}_{g, t}=\frac{\lambda_{g, t}}{h_{t}}$ the generalized indicator variable.

The following steps should be taken in order to obtain the test statistic:

(i) Using a consistent estimate of $\theta$, one calculates the residuals as suggested above, the gradient and indicator variables;

(ii) One regresses the indicator variables $\left(\tilde{\lambda}_{g, t}=\frac{\lambda_{g, t}}{h_{t}}\right)$ at gradient $\left(\nabla_{\theta} \tilde{\nu}_{t}\right)$, and then one calculates the respective residuals $\hat{\tilde{\lambda}}_{t}{ }^{6}$

(iii) Thereafter, one proceeds to the regression of a vector of ones in the product of the generalized residual by the residual of regression of item (ii) $\left(\hat{\tilde{\lambda}}_{t} \phi_{t}\right)$, calculating statistic $L M=T R^{2}$.

This statistic has an asymptotic chi-square distribution with degrees of freedom equal to the number of indicator variables $(Q)$ used in step (ii).

Several sources of misspecification can be tested using this procedure. The first type concerns the possibility that residual heteroskedasticity is found in the data. Therefore, a richer structure in the autocorrelation term in the variance should

\footnotetext{
${ }^{5}$ Engle and Sheppard (2001) report that the estimation of a BEKK with 1 autoregressive lag and 1 moving average component in the variance with 10 series can take around 12 hours to be converted on a Pentium III - 700 using a Matlab routine.

${ }^{6}$ This procedure is equivalent to regressing the indicator variable on the gradient of the likelihood function in the first stage.
} 
be implemented. Another source of misspecification is related to the presence of some kind of asymmetry in the estimated models.

\section{Database Description}

In this paper, we seek to investigate to what extent there is a common pattern of heteroskedasticity in the series of sovereign bonds of four emerging countries: Brazil, Argentina, Mexico and Russia. The series were collected from Bloomberg and were built by J. P. Morgan. A daily frequency was used for data between January 1, 1994 and December 31, 2002.

The Emerging Markets Bond Index is calculated using a portfolio of sovereign bonds of a given country. A more in-depth description of the method used to construct these indices can be found in Morgan (1995). The behaviors of this index and of the returns are shown in Figure 1.

Corr_ARG_BRA_BEW_FULL

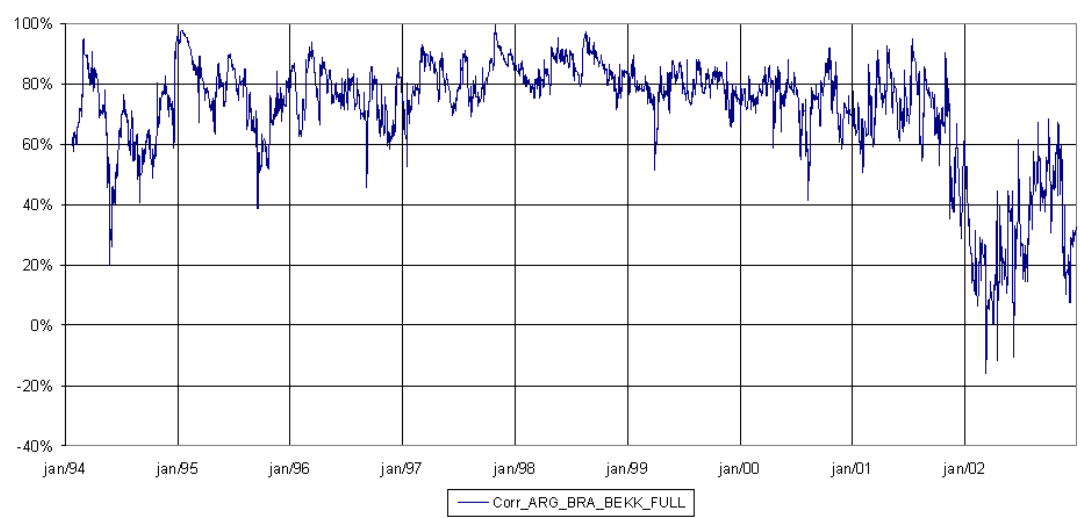

Figure 1

Estimated correlation between Argentina and Brazil - full T-BEKK model $(1,2,2)$

\section{Results}

\subsection{Prefiltering of the data}

Given that the multivariate models to be estimated are extremely heavy, the data were prefiltered in order to remove the whole linear structure from the returns, which were present in the first moment of the series. A VAR was run and the number of lags was determined by using information criteria and/or by the significance of the lag coefficients using standard deviations that are robust to heteroskedasticity. 


\subsection{Presentation of the results}

Based on the Matlab routines built by Sheppard \& Engle, ${ }^{7}$ we estimated the simplest versions of the models described above. For the BEKK, diagonal BEKK, constant correlation, and DCC-Engle models, we used the routines developed by the aforementioned authors. These routines require that the data be prefiltered, and the residual series with zero mean are the initial data for these routines. Therefore, it is possible to estimate only the parameters related to variance.

With regard to factor models, Lin (1992) was used as major reference. As the routines were not readily available, we decided to build them. The difficulty in the estimation lies in imposing restrictions of nonnegativity and stability. Two types of routines were developed. In the first one, one assumes that the common factors are known. In the second one, the common factors are estimated after the imposition of a condition of identification of these factors.

\subsection{Gaussian and symmetric multivariate models}

Table 1 shows the results obtained for the estimation of multivariate models. The estimated models were the diagonal and full BEKK, the factor model with known and unknown factors, the DCC-Engle, IDCC-Engle, DCC-TT and CC models. The best results in terms of information criteria were obtained for the DCC-Engle model followed by the BEKK model. The models with the worst performance were the factor models. The major reason for such results is that the only source of conditional volatility comes from common factors, with no idiosyncratic factors for heteroskedasticity. In addition, time correlation is also constant, which is probably a very restrictive hypothesis.

Table 2 shows the results for the rejection of the null hypothesis that the restrictive versions of the models given by diagonal BEKK and constant correlation, which are fitted into the full BEKK and DCC-TT models, respectively, are good simplifications of the general model. Two conclusions can be drawn from this:

a) models that imply constant correlations do not provide a good representation of the data and;

b) there is some kind of interdependence in the volatilities of the various assets due to the rejection of the hypothesis of diagonality in the BEKK model.

\footnotetext{
${ }^{7}$ The routines can be obtained from: http://www.kevinsheppard.com/research/ucsd_garch/ ucsd_garch.htm.
} 


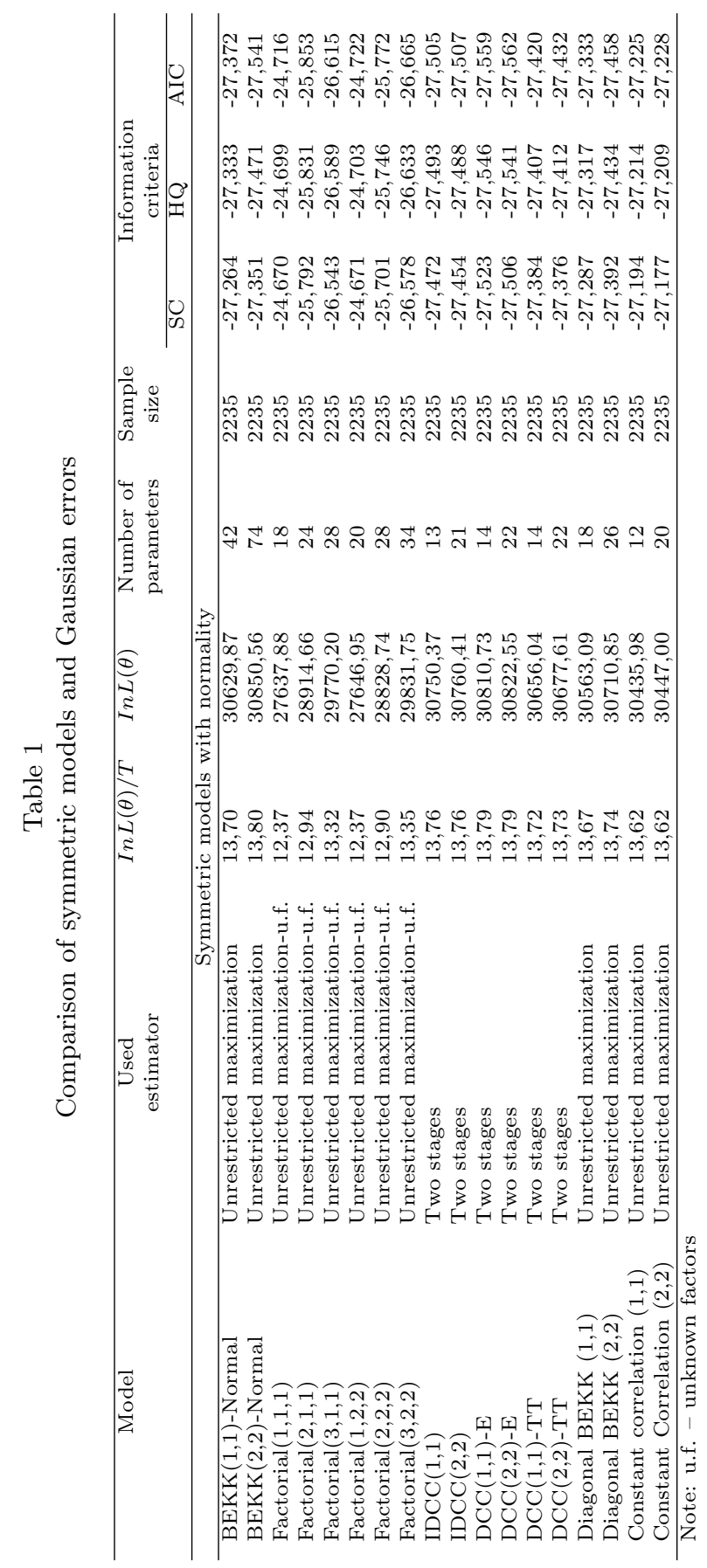


Table 2

Comparison of symmetric models and Gaussian errors

\begin{tabular}{llccc}
\hline $\begin{array}{c}\text { Unrestricted } \\
\text { model }\end{array}$ & \multicolumn{1}{c}{$\begin{array}{c}\text { Restricted } \\
\text { model }\end{array}$} & $\begin{array}{c}\text { Test } \\
\text { statistic }\end{array}$ & $\begin{array}{c}\text { Degree of } \\
\text { freedom }\end{array}$ & Chi-square \\
\cline { 5 - 5 } & & & 48 & $p$-value \\
\hline BEKK $(2,2)$ - Normal & BEKK $(2,2)$ - Diagonal & 279,41 & 24 & $0,0000 \%$ \\
BEKK $(1,1)$ - Normal & BEKK $(1,1)$ - Diagonal & 133,57 & $2400 \%$ \\
BEKK $(2,2)$ - Normal & BEKK $(1,1)$ - Diagonal & 574,94 & 56 & $0,0000 \%$ \\
DCC-TT $(2,2)$ & CC $(2,2)$ & 440,12 & 2 & $0,0000 \%$ \\
DCC-TT $(2,2)$ & CC $(2,2)$ & 461,21 & 2 & $0,0000 \%$ \\
\hline
\end{tabular}

\subsection{Is there a sign of misspecification in the estimated model?}

Using the tests described in subsection 3.2 .

The following indicator variables were used for the specification tests performed in this section:

$$
\begin{aligned}
\lambda_{1 t} & =\left[\varepsilon_{1 t-\max (p, q)-1}^{2}, \cdots, \varepsilon_{4 t-\max (p, q)-1}^{2}\right] \\
\lambda_{2 t} & =\left[I\left(\varepsilon_{1 t-1}>0\right), \cdots, I\left(\varepsilon_{4 t-1}>0\right)\right] \\
\lambda_{3 t} & =\left[\varepsilon_{1 t-1}^{2} I\left[\varepsilon_{1 t-1}>0\right], \cdots, \varepsilon_{4 t-1}^{2} I\left[\varepsilon_{4 t-1}>0\right]\right]
\end{aligned}
$$

The first set aims to check whether there is residual heteroskedasticity. The second and third sets seek to assess whether there is evidence of some type of asymmetry.

Table 3 presents the results for the full BEKK and DCC-E models. In general, the structure of the models was apparently able to prevent residual heteroskedasticity. With regard to asymmetry, there is evidence of some type of unmodeled asymmetry, chiefly for the BEKK model.

Two facts were not probably dealt with appropriately in the estimated models: excess kurtosis and asymmetry. Therefore, we are going to estimate full BEKK models with Student's $t$ distribution ${ }^{8}$ and asymmetric DCC models with univariate GJR models. The results are shown in the subsequent section.

\footnotetext{
${ }^{8}$ It is possible to propose an asymmetric BEKK model; however the number of parameters is too large and makes the estimation process too difficult. Thus, our decision was not to go in this direction as DCC models are easier to implement and allow modeling asymmetry.
} 


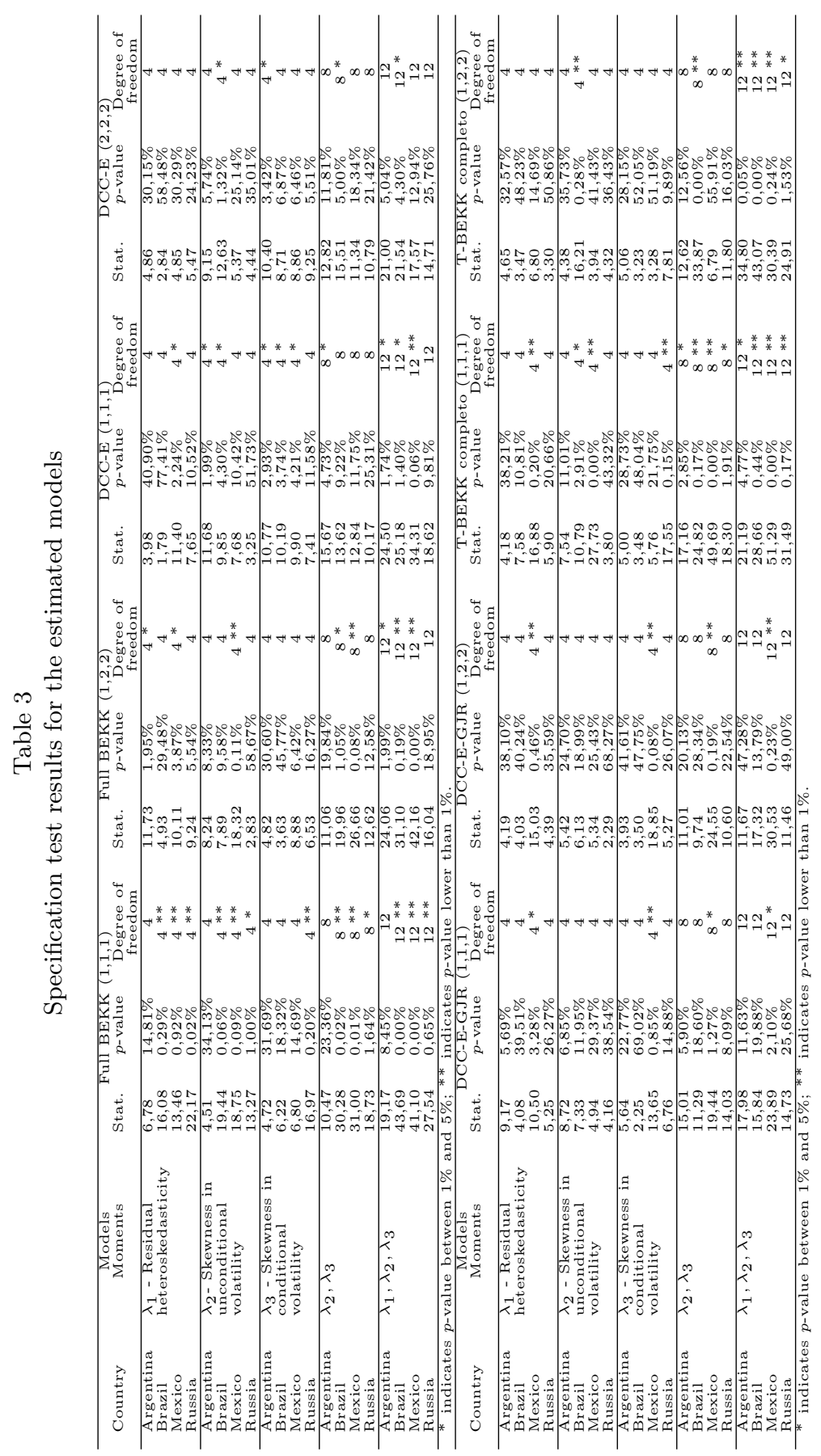




\section{Multivariate Models: Modeling Asymmetry and Excess Kurtosis}

The multivariate models presented herein can be generalized so as to allow for some type of asymmetry in the behavior of the series. In addition, models with 'heavier tails' than the normal distribution can be estimated using Student's $t$ distribution. In general, for univariate models, this type of procedure allows some gain in the description of financial data.

An extremely interesting alternative was proposed by Engle \& Sheppard in a series of recent papers, in which they combine some level of generality with some simplicity for the estimations. The DCC model can be generalized so as to include asymmetric components without losing its relative computational simplicity.

In an attempt to add asymmetry to the models, the DCC framework was combined with a threshold GARCH structure as proposed by Glosten et al. (1993) - GJR. This model is a particular case of a general model as the one described in Bollerslev et al. (1994). The general model is given by:

$$
\sigma_{t}^{\gamma}=\omega+\sum_{i=1}^{q}\left(\alpha_{i}^{+}\left(u_{t-i}^{+}\right)^{\gamma}+\alpha_{i}^{-}\left(u_{t-i}^{-}\right)^{\gamma}\right)+\sum_{j=1}^{p} \beta_{j} \sigma_{t-j}^{\gamma}
$$

where $u_{t}^{+}=\max \left\{u_{t}, 0\right\}$ and $u_{t}^{-}=\min \left\{u_{t}, 0\right\}$. In the model proposed by Glosten et al. (1993) we have that $\gamma=2$ and it is estimated with an additional restriction of a single threshold, i.e., $\alpha_{i}^{+}=\alpha_{i}^{-} \forall i \neq i_{\text {threshold }}=1$.

In general, the models, whose estimates are shown in Table 4 , have smaller information criteria than the models described in Table 1 . The results in Table 5 confirm that the Student's $t$ BEKK and DCC-E-GJR models provide a better representation of the data. Therefore, the models to be used in the subsequent analysis are the Student's $t$ BEKK and DCC-E-GJR. The results in Table 6 show that the DCC-E-GJR models have good specification results except for the equation that models the Mexican bonds. The Student's $t$ BEKK model is capable of removing the heteroskedasticity observed in the series; however, it is not capable of handling the existing asymmetry, which is somehow expected. On the other hand, the major restriction on the DCC-E-GJR model concerns the time structure imposed to model the correlations. Thus, both models will be used in the subsequent analysis. The figures for the estimated conditional correlations are shown in Figures 3 through 6 .

Table 4

Likelihood ratio tests

\begin{tabular}{|c|c|c|c|c|}
\hline Unrestricted Model & Restricted Model & Test statistic & $\begin{array}{l}\text { Degree of } \\
\text { freedom }\end{array}$ & $\begin{array}{l}\text { Chi-Square } \\
p \text {-value }\end{array}$ \\
\hline $\operatorname{BEKK}(1,1)-t$-student & $\operatorname{BEKK}(1,1)$ - Normal & 1175,10 & 33 & $0,0000 \%$ \\
\hline $\operatorname{BEKK}(2,2)-t$-student & $\operatorname{BEKK}(2,2)$ - Normal & 937,87 & 1 & $0,0000 \%$ \\
\hline $\operatorname{BEKK}(2,2)-t$-student & $\operatorname{BEKK}(1,1)$ - Normal & 1379,24 & 33 & $0,0000 \%$ \\
\hline $\operatorname{BEKK}(2,2)-t$-student & $\operatorname{BEKK}(1,1)-t$-student & 204,14 & 32 & $0,0000 \%$ \\
\hline DCC-E-GJR $(1,1)$ & DCC-E- $(1,1)$ & 196,74 & 4 & $0,0000 \%$ \\
\hline DCC-E-GJR $(2,2)$ & DCC-E- $(2,2)$ & 173,24 & 4 & $0,0000 \%$ \\
\hline DCC-E-GJR $(2,2)$ & DCC-E-GJR $(1,1)$ & 0,13 & 8 & $99,9999 \%$ \\
\hline
\end{tabular}




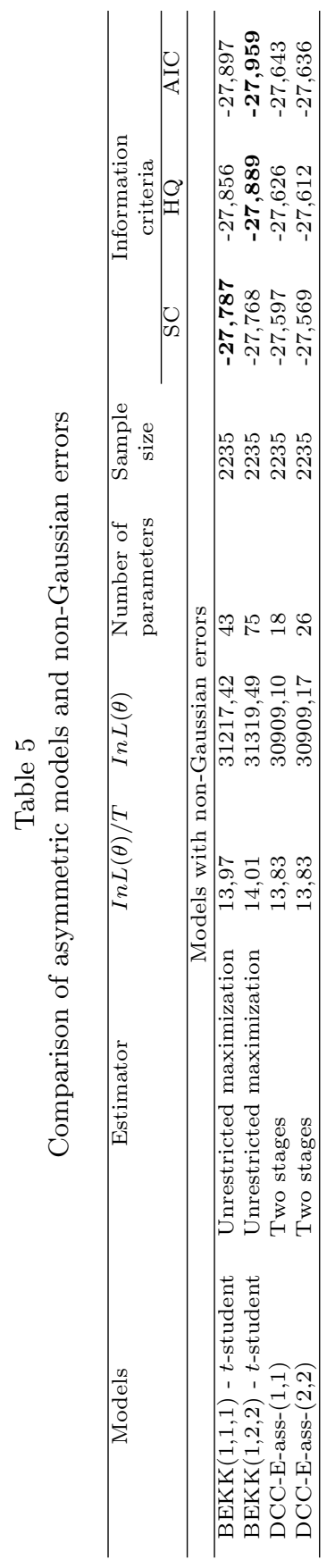




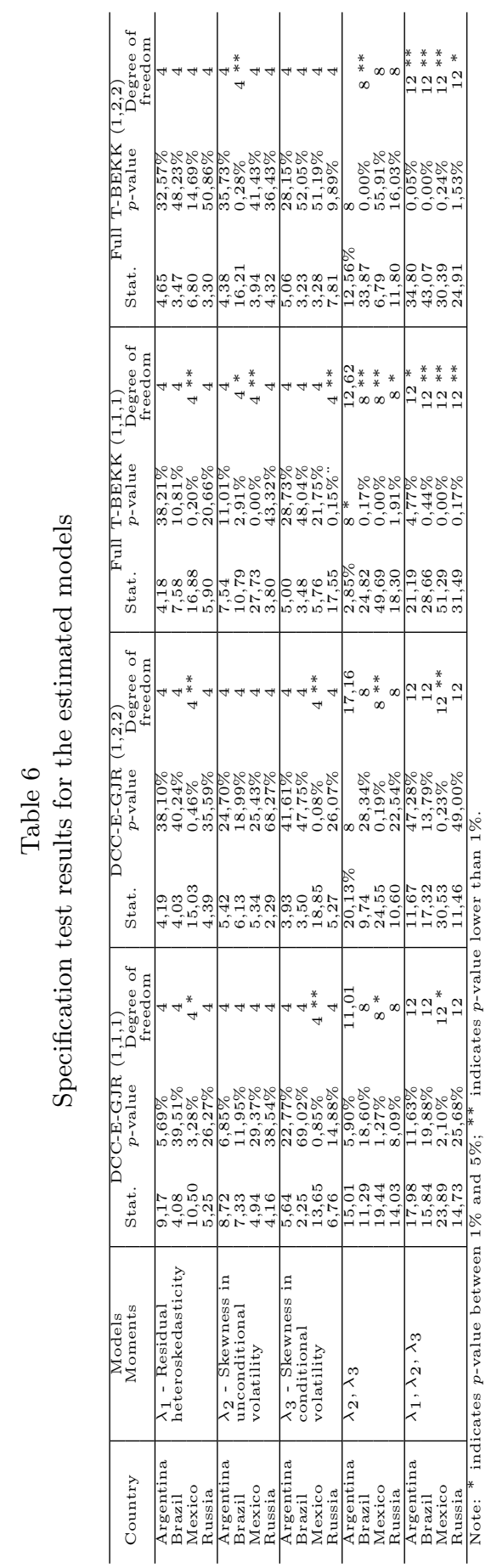




\section{Testing the Hypothesis of Structural Breaks in Crisis Periods}

The aim of this section is to investigate whether there is some evidence of structural break that can be associated with the financial crises suffered by Brazil, Mexico, Russia and Argentina. For instance, in the second half of 2001, some financial analysts indicated there was some "detachment" between Brazil and Argentina. From a technical standpoint, the volatility of Argentine assets was no longer causing volatility on Brazilian assets. This and some other assumptions alike can be tested using the theoretical framework proposed here.

Wooldridge's procedure $(1990,1991)$ introduced in the previous sections can also be used to detect some type of misspecification in the correlation structure of the series. The generalized residual can be calculated as follows: $u_{i j, t}^{*}=u_{i t} u_{j t}-$ $\rho_{i j, t}$. The term $\rho_{i j, t}$ represents the time correlation estimated by the model for assets $i$ and $j$ at time $t$ and the term $u_{i t} u_{j t}$ represents the products of standardized residuals estimated for assets $i$ and $j$ at time $t$. The value of term $u_{i j, t}^{*}$ is equal to zero, as expected. After that, one should use a procedure that is similar to the one above by using $u_{i j, t}^{*}$ in lieu of $\phi_{t}$.

As discussed above, the distinction between contagion and interdependence is associated with the comparative analysis of the behavior of time correlations before (calm period) and during the crises.

The following indicator variables were used for the specification tests performed in this section to investigate the existence of unstable correlation structures and whether such instability can be associated with crisis periods:

$$
\begin{aligned}
\lambda_{4 t}= & {\left[\varepsilon_{1 t-1} \varepsilon_{2 t-1}, \varepsilon_{1 t-1} \varepsilon_{3 t-1}, \cdots, \varepsilon_{3 t-1} \varepsilon_{4 t-1}\right] } \\
\lambda_{5 t}= & {\left[I\left(\varepsilon_{1 t-1}<0, \varepsilon_{2 t-1}<0\right) I\left(\varepsilon_{1 t-1}<0, \varepsilon_{3 t-1}<0\right), \cdots,\right.} \\
& \left.I\left(\varepsilon_{3 t-1}<0, \varepsilon_{4 t-1}<0\right)\right] \\
{\left[\lambda_{6 t}, \cdots, \lambda_{11 t}\right]=} & {\left[D_{\text {Mexican Crisis }}, D_{\text {Asian Crisis }}, D_{\text {Russian Crisis }},\right.} \\
& D_{\text {Brazilian Crisis } 1999, D_{\text {Argentine Crisis }},} \\
& \left.D_{\text {Brazilian Crisis 2002 }}\right]
\end{aligned}
$$

The indicator variables in equation 12 are supposed to assess whether there is some remaining structure in the correlations of the standardized residuals. The variables in equation 13 are supposed to assess if simultaneous negative shocks produce some effect on correlations. The variables in equation 14 test whether conditional correlations changed during the crisis periods.

The dummies for the crises were arbitrarily defined based on exogenous information provided by the econometrician. The duration of the crisis was defined as two months. A distinction was made between the onset of the crisis, which can be observed by associating the information on economic history with the peak volatilities observed in the models estimated in the null hypothesis and the 'making' of the crisis, since there exists a period that precedes the onset of the crisis, 
in which agents know about the high probability of a crisis and then begin to make decisions and to adjust themselves to its probable effects. Also, the month immediately before the onset of the crisis was arbitrarily defined as the period that originated the crisis. In the estimated models, there is no asset of any Asian country; so, it was also necessary to define the period in which the Asian crisis arose. As a set of countries was subsequently affected, the period of crisis was the same one used by Baig and Goldfajn (1999), which ranges from July 1997 to May 1998.

Table 7 shows the results of the tests for the dynamic correlations. Evidence is not the same for the two models. In the DCC-E-GJR models, virtually all the proposed dummies are significant, indicating that the models do not describe well the correlations in crisis periods. However, some results are not quite intuitive. For instance, there is some general perception that Brazilian crisis in 1999, and especially the Argentine crisis in 2001, had negligible effects on other countries, which are not confirmed by the results of the DCC-E-GJR model.

In addition, Table 7 also presents the same tests for the Student's $t$ BEKK models. In this case, the results seem to be more intuitive, confirming to a certain extent the inference derived from the common sense. The Mexican, Asian and Russian crises caused more "contagion" in other countries, but the Argentine and Brazilian crises in 1999 and 2002 had no or little effect on international markets.

Figure 2 shows the conditional volatilities estimated for each of the countries. In general, the Russian crisis appears to have been the strongest of all crises. The level of volatility is certainly one of the highest of the series. In terms of intensity, the Argentine crisis in 2002 also implied an increase in volatility. Unlike the Russian crisis, this increase in volatility was not followed by an increase in volatility in other countries. The Brazilian crises of 1999 and 2002 seem to have been similar to the Mexican crisis in terms of volatility. Figure 2 allows inferring a pattern of transmission for the crises. The Mexican crisis produced effects on other countries, without any exception. The same applies to the Russian crisis. On the other hand, the Brazilian crisis in 2002 and the Argentine crisis do not seem to have caused remarkable effects on other countries. 
Corr_BRA_MEX_BEK__FULL

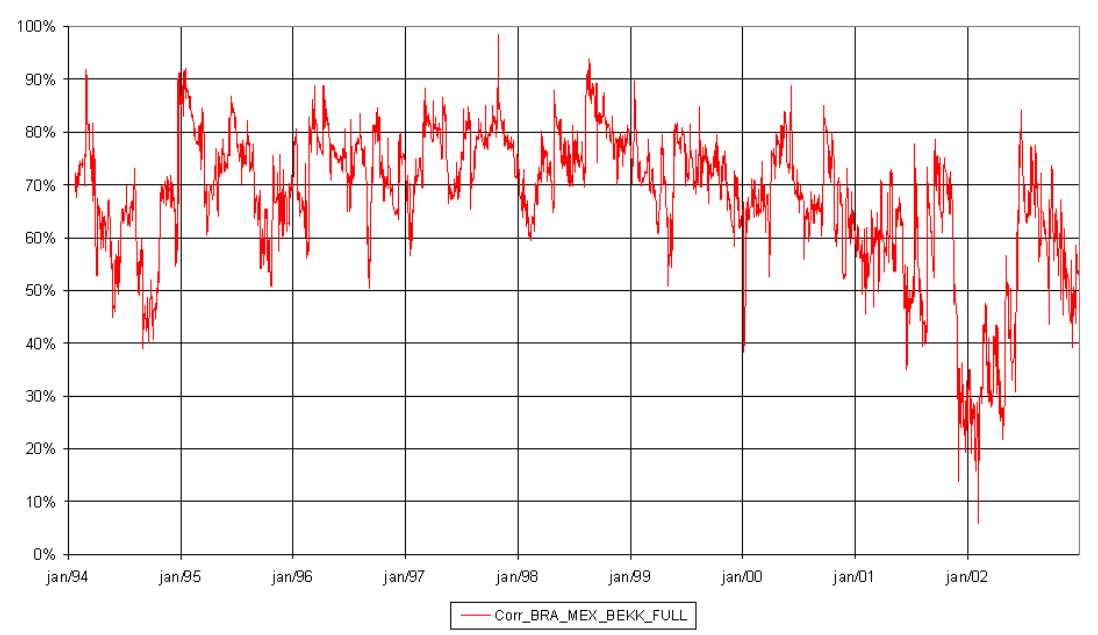

Figure 2

Estimated correlation between Brazil and Mexico - full T-BEKK model $(1,2,2)$

In terms of conditional correlation, the highest values were found amongst Latin American countries (Brazil, Argentina and Mexico). See Figures 3 through 6. The level of correlation between Russia and other countries is much lower. The correlation pattern seems to have changed in the course of 2002 for correlations between Brazil and Argentina and other countries, indicating that the increase in volatility in the first set of bonds was not followed by an increase in conditional covariances and, consequently, in conditional correlations. Therefore, it was possible to build a portfolio of sovereign bonds that allowed for risk diversification, a fact that may not have occurred in other crisis periods. 
Emerson Fernandes Marçal and Pedro L. Valls Pereira

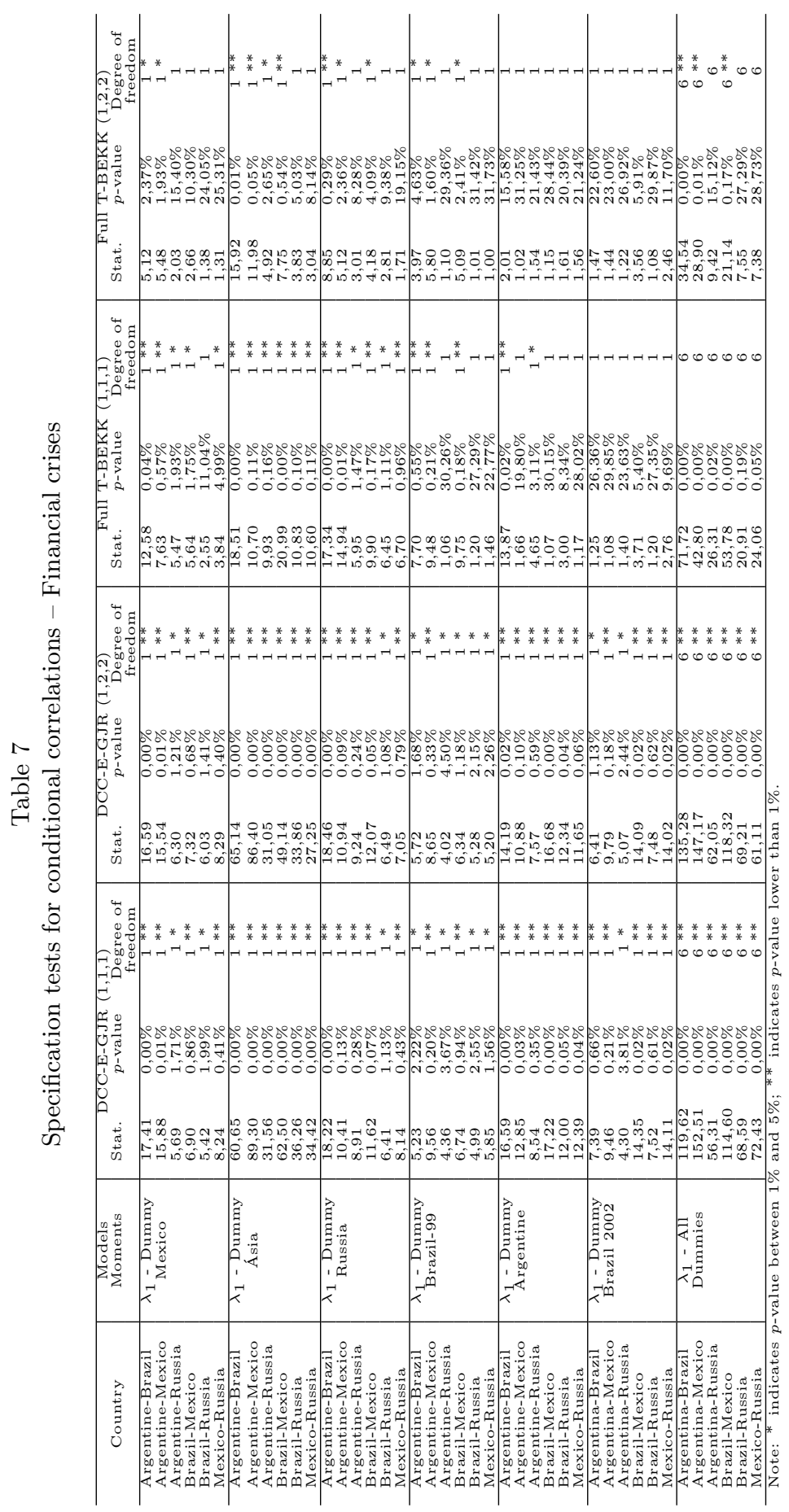


Corr_BRA_RUS_BEKK_FULL

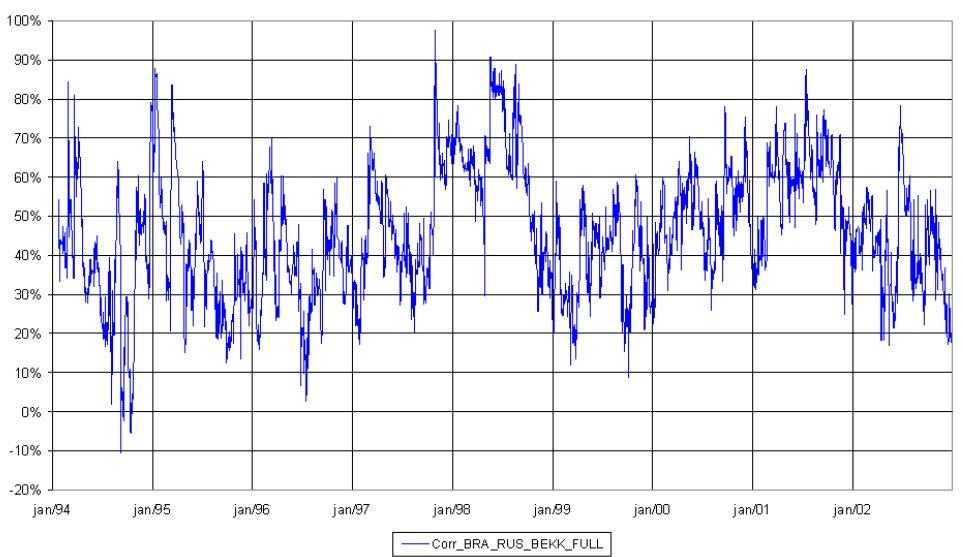

Figure 3

Estimated correlation between Brazil and Russia - full T-BEKK model $(1,2,2)$

COrr_ARG_MEX_EEKK_FULL

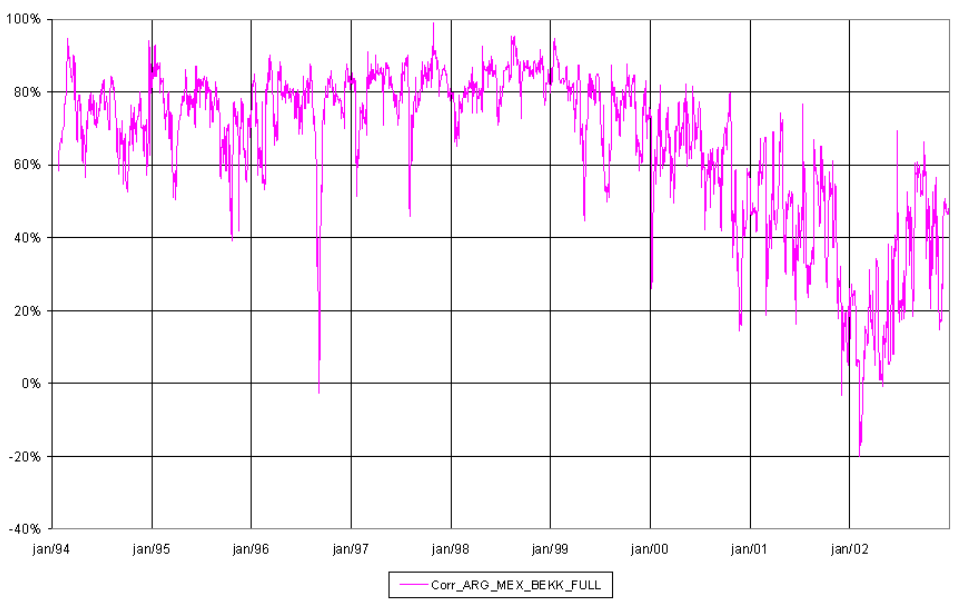

Figure 4

Estimated correlation between Argentina and Mexico - full T-BEKK model $(1,2,2)$ 
Corr_ARG_RUS_BEKK_FULL

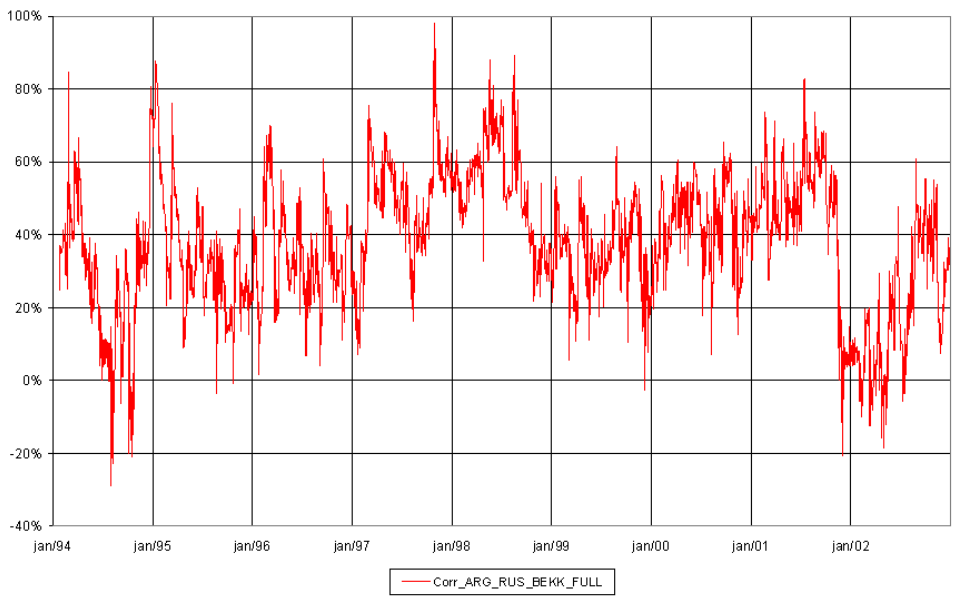

Figure 5

Estimated correlation between Argentina and Russia - full T-BEKK model $(1,2,2)$

COrr_MEX_RUS_BEKK_FULL

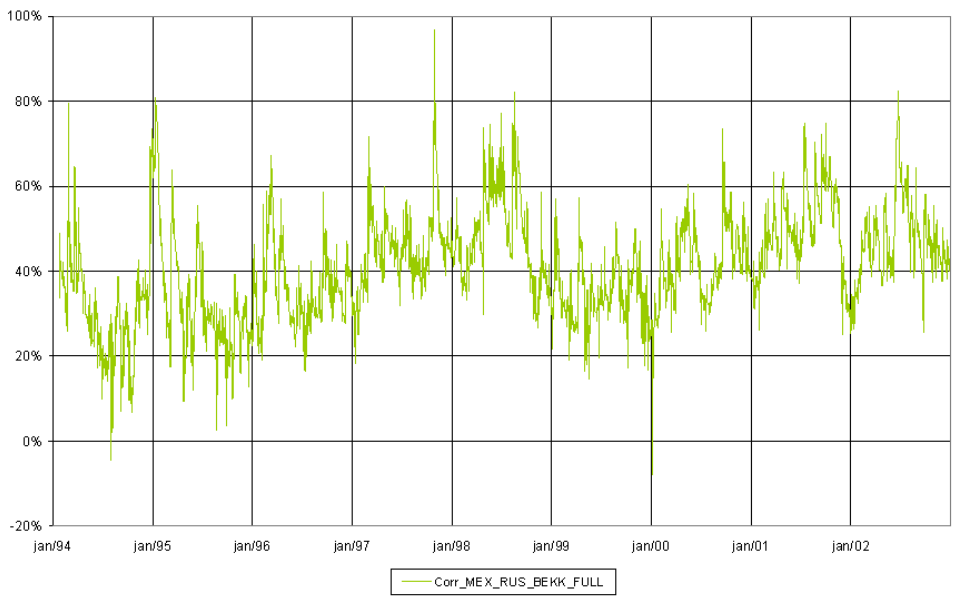

Figure 6

Estimated correlation between Mexico and Russia - full T-BEKK model $(1,2,2)$ 
Testing the Hypothesis of Contagion Using Multivariate Volatility Models

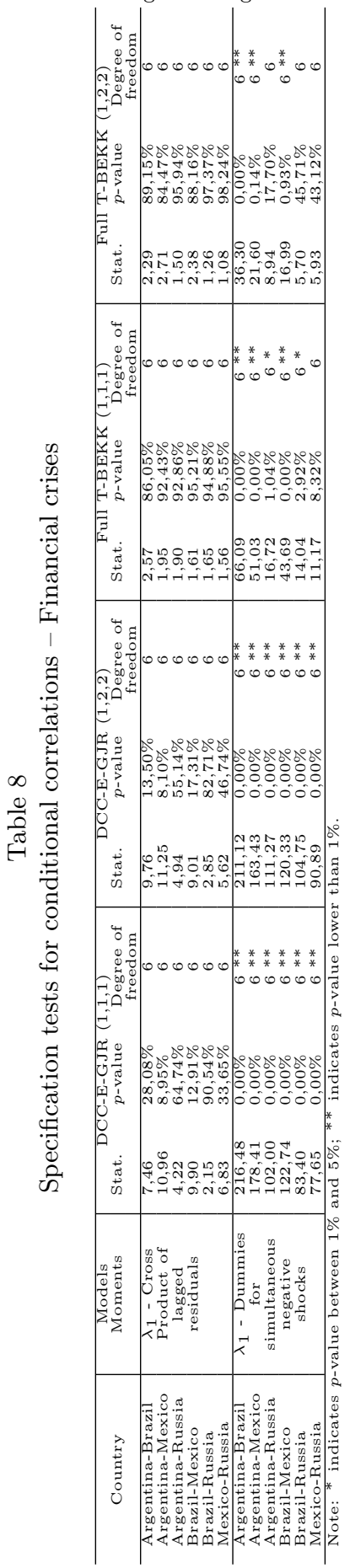


Finally, in Table 8, we test whether there is unmodeled conditional correlation in the DCC-E-GJR and Student's $t$ BEKK models. Both models pass the specification test so that there is no correlation structure left in the standardized residuals. However, there seems to be some kind of unmodeled asymmetry in both models on the test for simultaneous negative shocks, since indicator variables are significant in terms of correlations.

\section{Comparison with other Literature Studies ${ }^{9}$}

One study that seeks to model and test the existence of interdependence is the one conducted by Morais and Portugal (2001). The authors estimate a stochastic volatility model proposed by Harvey et al. (1994). They find evidence that the volatility of the returns of PAR bonds (analyzed bonds) is correlated. A possible criticism is that some bonds have a low level of liquidity. A natural extension of this study would be to model the volatility of assets using multivariate GARCH models. The authors did not follow this line of research because of the relative computational simplicity of stochastic volatility models. Another possibility raised by Lopes and Migon (2002) consists in modeling the return of stock indices of several emerging countries. Both studies provide evidence of components that are common in the series.

Karolyi (1995) estimates some multivariate GARCH models described in the previous section to assess to what extent the U.S. and Canadian stock markets are interconnected in terms of returns and volatility. Finally, Baig and Goldfajn (1999) assess the existence of contagion among assets (exchange rates and shares) in Asian countries. They analyze the following countries: Indonesia, Thailand, Korea, Malaysia and the Philippines. The method to check for the existence of contagion is similar, to some extent, to the one proposed in the present study. The authors' basic idea is to compare the correlations of several assets in the period with the correlations observed in the calm period. An increase in correlations is seen as evidence of contagion. The results obtained by the authors indicate some level of contagion, especially in exchange rates and sovereign spreads. They seek to test if, when corrected by fundamentals, correlations still tend to increase in crisis periods. This option could have been used in the present study and would have required us to model the first moment of the series as well, which would make models, such as BEKK, even heavier and difficult to estimate. Nevertheless, DCC-E and DCC-TT models offer this possibility.

\footnotetext{
${ }^{9}$ For univariate models, see Issler (1999), Almeida and Valls Pereira (2000) and Valls Pereira et al. (1999).
} 


\section{Conclusion}

The present paper used a wide range of multivariate models to model the returns of sovereign bonds of various countries. Some conclusions should be highlighted. There is evidence of interdependence between the assets of the analyzed countries. This is an intuitive result as out of the four countries, Brazil and Argentina, followed by Mexico, have good commercial ties and are seen by economic analysts as belonging to the same category within emerging countries.

In addition, there appears to be some evidence that the estimated volatility structures were not constant during the various financial crises that occurred throughout the analyzed period. This is evidence of contagion. In particular, the Mexican, Asian and Russian crises had remarkable effects. On the other hand, the Brazilian and Argentine crises, in 2002, did not have a large impact and were restricted to the respective countries of origin.

There is evidence of some asymmetric behavior in volatilities. The negative shocks seem to have different effects on the level of volatility and of correlations, which corroborates one of the stylized facts in Finances. This result can be assessed through some of the results reported for the specification tests and also based on the superiority obtained by the models in which some kind of asymmetry was allowed.

Finally, there is evidence that bad news that simultaneously affected these countries, through the effect of the indicator variables defined in equation (9), also has an effect on the increase of volatility and of correlations.

\section{References}

Almeida, N. M. C. G. \& Valls Pereira, P. L. (2000). Mudança de regime em volatilidade: Os modelos SWGARCH. Texto para Discussão 11, FEA-USP, São Paulo.

Baig, T. \& Goldfajn, I. (1999). Financial market contagion in the Asian crises. IMF Staff Papers, 46(3):167-195.

Bauwens, L., Laurent, S., \& Roumbouts, J. V. K. (2003). Multivariate GARCH models: A survey. Core Discussion Paper 31, Université Catholique de Louvain.

Bazdresch, S. \& Werner, A. M. (2000). Contagion of international financial crises: The case of Mexico. Dirección General de Investigación Económica, Banco de México.

Bollerslev, T. (1986). Generalized autoregressive conditional heteroskedasticity. Journal of Econometrics, 31:307-327.

Bollerslev, T. (1990). Modelling the coherence in short-run nominal exchange rates: A multivariate generalized ARCH approach. Review of Economics and Statistics, 72:498-505. 
Bollerslev, T. (2001). Past developments and future changes. Journal of Econometrics, 100:41-52.

Bollerslev, T., Engle, R. F., \& Nelson, D. B. (1994). ARCH models. In Handbook of Econometrics, chapter 49. Elsevier.

Bollerslev, T., Engle, R. F., \& Wooldridge, J. M. (1988). A capital asset pricing model with time varying covariances. Journal of Political Economy, 96:116-131.

Calvo, S. \& Reinhart, C. (1996). Capital flows to Latin America. Is there evidence of contagion effects? In Calvo, G., Goldstein, M., \& Hochreiter, E., editors, Private Capital Flows to Emerging Markets. Institute for International Economics, Washington, DC.

Corsetti, G., Pericoli, M., \& Sbracia, M. (2003). Some contagions, some interdependence - More pitfalls in tests of financial contagion. Mimeo.

Dornbush, R., Park, Y. C., \& Claessens, S. (2000). Contagion: Understanding how it spreads. The World Bank Observer, 15:177-197.

Dungey, M., Fry, R., Gonzalez-Hermozilio, B., \& Martin, V. L. (2004). Empirical modeling of contagion: A review of methodologies. IMF Working Paper 78.

Engle, R. F. (1982). Autoregressive conditional heteroscedasticity with estimates of the variance of United Kingdom. Econometrica, 50:987-1007.

Engle, R. F. (2002). Dynamic conditional correlation: A simple class of multivariate generalized autoregressive conditional heteroskedasticity models. Journal of Business \& Economics Statistics, 20(3):339-350.

Engle, R. F. \& Kroner, K. F. (1995). Multivariate simultaneous generalized ARCH. Econometric Theory, 11:122-150.

Engle, R. F. \& Sheppard, K. (2001). Theoretical and empirical properties of dynamic conditional correlation multivariate GARCH. NBER Working Paper 8554 .

Forbes, K. \& Rigobon, R. (2002). No contagion, only interdependence: Measuring stock market co-movements. Journal of Finance, 57(5):2223-2261.

Franses, P. H. \& van Dijk, D. (2000). Non-Linear Time Series Models in Empirical Finance. Cambridge University Press.

Glosten, L. R., Jagannathan, R., \& Runkle, D. (1993). On the relation between the expected value and the volatility of the normal excess return on stocks. Journal of Finance, 48:1779-1801. 
Harvey, A., Ruiz, E., \& Shephard, N. (1994). Multivariate stochastic variance models. Review of Economic Studies, 61:247-264.

Issler, J. V. (1999). Estimating and forecasting the volatility of Brazilian finance series using ARCH models. Revista Brasileira de Econometria, 19(1):5-56.

Karolyi, G. A. (1995). A multivariate GARCH model of international transmissions of stocks returns and volatility: The case of United States and Canada. Journal of Business \& Economic Statistics, 13(1):11-25.

Lin, W. L. (1992). Alternative models for factor GARCH models. Journal of Applied Econometrics, 7:259-279.

Lopes, H. F. \& Migon, H. S. (2002). Comovements and contagion in emergent market: Stock indexes volatilities. Case Studies in Bayesian Statistics, VI:285300 .

Masson, P. \& Mussa, M. (1995). The role of the fund: Financing and its interactions with adjustments and surveillance. IMF Working Paper 50.

Masson, P. R. (1998). Contagion: Monsoonal effects, spillover and jumps between multiple equilibria. IMF Working Paper 142.

Masson, P. R. (1999). Multiple equilibria, contagion and the emerging market crises. IMF Working Paper 64

Morais, I. A. C. \& Portugal, M. (2001). Characteristics of stochastic volatility for Latin America's par bonds. Seminário do FinanceLab, IBMEC Business School, agosto, São Paulo.

Morgan, J. P. (1995). Introducing the Emerging Markets. Bond Index Plus, New York.

Pericoli, M. \& Sbracia, M. (2001). A primer on financial contagion. Journal of Economic Surveys, 17:571-608.

Pesaran, M. H. \& Pick, A. (2003). Econometric issues in the analysis of contagion. Cesifo Working Paper 1176, Cambridge.

Pritsker, M. (2001). The channels of finance contagion. In Claessens, S. \& Forber, K., editors, International Financial Contagion. Kluwer Academic Publishers.

Tse, Y. K. (2000). A test for constant correlations in a multivariate GARCH model. Journal of Econometrics, 98:107-127.

Tse, Y. K. \& Tsui, A. K. C. (2002). A multivariate generalized autoregressive conditional heteroscedasticity model with time-varying correlations. Journal of Business and Economic Statistics, 20(3):351-362. 
Valls Pereira, P. L., Hotta, L. K., Souza, L. A. R., \& Almeida, N. M. C. G. (1999). Alternative models to extract asset volatility: A comparative study. Revista Brasileira de Econometria, 19(1):57-110.

Wooldridge, J. (1990). A unified approach to robust, regression based specifications tests. Econometric Theory, 6:17-43.

Wooldridge, J. (1991). On the application of robust, regression based diagnostics to models of conditional means and conditional variances. Journal of Econometrics, $47: 5-46$ 